\title{
Prevalence of Obesity, Metabolic Syndrome, Impaired Fasting Glycemia, and Diabetes in Selected Villages of Bali, Indonesia
}

\author{
Ketut Suastika ${ }^{1 *}$, Pande Dwipayana ${ }^{1}$, I Made Ratna Saraswati ${ }^{1}$, Wira Gotera ${ }^{1}$, Anak Agung Gde Budhiarta ${ }^{1}$, \\ I Nengah Dwi Sutanegara ${ }^{1}$, I Gusti Ngurah Gunadi², Ketut Badjra Nadha², Wayan Wita², Ketut Rina², \\ Awar Santoso 3 , Kinuyo Matsumoto ${ }^{4}$, Naemi Kajiwara ${ }^{4}$, Hiroshi Taniguchi ${ }^{5}$
}

1Department of Internal Medicine, Udayana University/Sanglah Hospital, Denpasar, Bali, Indonesia; 2Department of Cardiovascular Medicine, Udayana University/Sanglah Hospital, Denpasar, Bali, Indonesia; ${ }^{3}$ Harapan Kita Hospital, Jakarta, Indonesia; ${ }^{4}$ Graduate School of Life Science, Kobe Women's University, Kobe, Japan; and 5Visiting Professor at Udayana University, Denpasar, Indonesia

\begin{abstract}
Aims/Introduction. To know the prevalence of obesity, metabolic syndrome, impaired fasting glycemia and diabetes in the population of Bali.

Materials and Methods. A cross-sectional study enrolling 1840 subjects, aged 13-100 years with male-to-female ratio of $972 / 868$, were studied at seven villages across the island of Bali.

Results: The prevalence of central obesity was 35\% (male, 27.5\%; female, 43.4\%); metabolic syndrome (MS), 18.2\% (male, 16.6\%; female, 20.0\%); impaired fasting glycemia (IFG), 13.1\% (male, 14.3\%; female, 12.4\%); and diabetes mellitus (DM), 5.9\% (male, 6.1\%; female, 5.7\%). The subjects who had 1, 2, 3, 4, and 5 components of MS were $34.6 \%, 23.8 \%, 13.0 \%, 4.3 \%$, and $0.9 \%$ respectively. The population in two tourist areas (Legian and Ubud) had the highest prevalence of central obesity $(61.2 \%$ and $70.1 \%)$, but they did not necessarily have a higher prevalence of DM. The two tourist areas (Legian, 24.1\%; and Ubud, 21\%) as well as Sangsit village (23.3\%) have the highest prevalence of MS.

Conclusions. The prevalence of obesity, MS, IFG and DM were comparatively low. Analysis across the villages revealed that higher prevalence of central obesity was not necessarily associated with higher prevalence of DM. There is a need to further study the risk of obesity on MS and DM in tourist areas of Bali.
\end{abstract}

Key words: obesity, metabolic syndrome, impaired fasting glycemia, diabetes, population of Bali

\section{Introduction}

The prevalence of obesity, metabolic syndrome (MS), and diabetes mellitus (DM) are increasing globally. Metabolic syndrome is a cluster of risk factors that predisposes an individual to atherosclerosis which may eventually lead to increased risk of cardiovascular morbidity and mortality. There is now general agreement regarding the criteria (characteristic features) often used for the diagnosis of the syndrome, i.e. glucose intolerance, obesity (Body Mass Index $[\mathrm{BMI}])$, raised blood pressure and dyslipidemia with elevated triglycerides, low levels of high density lipoprotein [HDL] cholesterol; but different definitions use different cut-off points for the parameters used for diagnosis and also different concepts of mandatory inclusion criteria. ${ }^{1}$ Although insulin resistance is considered a major pathological influence, only the World Health Organization (WHO) and European Group for the study of Insulin Resistance (EGIR) definitions include it in the diagnostic criteria and only the International Diabetes Federation (IDF) definition uses waist circumference as a

ISSN 0857-1074

Copyright $(2) 2011$ by the JAFES

Received July 25, 2011. Accepted October 5, 2011. mandatory criterion..$^{1-3}$ Insulin resistance is closely related to central obesity, i.e. excessive abdominal fat deposition..$^{2,3}$ The published prevalence of MS varies because of several factors, e.g. different diagnostic criteria and parameters used, differences in ethnicity, age, and sex. However, the prevalence of MS has the tendency to increase along with the increase in the prevalence of obesity, especially central obesity. ${ }^{4}$ The prevalence of impaired glucose tolerance (IGT) and DM are also increasing globally. Around $60 \%$ of the obese population also have DM. ${ }^{5}$

The primary objective of the study was to know the prevalence of obesity, MS, glucose intolerance (prediabetes and DM) in the population of Bali. To our knowledge there is a paucity of published baseline data on obesity, MS, and glucose intolerance, i.e., prediabetes and DM, especially for the people of the rural areas of Bali, and will be needed for health intervention and research as the influx of global tourism into the Island would be expected to have a wide ranging impact on the lifestyle and socialeconomic status of the population.
Corresponding author: Ketut Suastika, MD, PhD

Endocrinology and Metabolism Division, Department of Internal Medicine,

Faculty of Medicine Udayana University/Sanglah Hospital

Jl. Kesehatan, Denpasar 80224 Bali Indonesia

Tel. No.:: +62 361246274

Mobile No.: +62 811380916

Fax No: +62 361235982

E-mail:ksuas@yahoo.com 


\section{Materials and Methods}

A cross-sectional survey study was carried out on obesity, MS and its components, and glucose intolerance, i.e., prediabetes and DM in the population of seven villages (6 villages and 1 suburban area) across the island of Bali, Indonesia. The villages were Sangsit (seashore area, 471 subjects), Pedawa (mountainous area, native Balinese, 294 subjects), Ubud (lowland and tourist area, 301 subjects), Tenganan (upland area, native Balinese, 81 subjects), Ceningan (offshore island, 305 subjects), Legian (coastal and tourist area, 288 subjects), and Pengelipuran (upland area, 100 subjects). Purposive sampling was done to represent seashore vs. highland area, native vs. non-native Balinese, and tourist vs. non-tourist area; and to explore differences in prevalence in these settings. Figure 1 is a map of Bali showing the location of the seven villages used in the study. A total number of 1840 subjects were recruited by random sampling (stratified for larger villages by sub-village: Sangsit, Pedawa, Ubud, Legian). The number of samples in each village was primarily based on target sample. The variables measured included age, waist circumference, body mass index, blood pressure, lipid plasma, fasting blood glucose. Fasting blood samples were drawn after at least 10 hours of overnight fasting. Criteria for obesity was based on the 2000 WHO recommendations for the Asia Pacific population. ${ }^{6}$ Classification of impaired fasting glycemia (IFG) and DM was based on the American Diabetes Association (2009): i, IFG if fasting blood glucose levels was $\geq 100 \mathrm{mg} / \mathrm{dL}$ and $<126 \mathrm{mg} / \mathrm{dL}$; and diabetes if fasting blood glucose level was $\geq 126 \mathrm{mg} / \mathrm{dL}$. $^{7}$ Diagnosis of MS was confirmed based on the criteria of a Joint Statement of IDF, NIH, AHA, WHF, IAS, and IASO (2009). Metabolic syndrome was diagnosed if 3 or more of the following 5 criteria are present: elevated waist circumference (male $>90 \mathrm{~cm}$, female $>80 \mathrm{~cm}$ ); elevated triglycerides (drug treatment for elevated triglycerides is an alternate indicator; $\geq 150 \mathrm{mg} / \mathrm{dL}$ ); reduced HDL cholesterol (drug treatment for reduced HDL cholesterol is an alternate indicator; $\leq 40 \mathrm{mg} / \mathrm{dL}$ in males, and $\leq 50 \mathrm{mg} / \mathrm{dL}$ in females); elevated blood pressure (antihypertensive drug treatment in a patient with a history of hypertension is an alternate indicator; systolic $\geq 130$ and/or diastolic $\geq 85 \mathrm{~mm} \mathrm{Hg}$ ); elevated fasting glucose (drug treatment of elevated glucose is an alternate indicator; $\geq 100 \mathrm{mg} / \mathrm{dL}){ }^{8}$

Statistical methods used for data analysis include descriptive presentation, independent t-test and chi square, with significance value at $\mathrm{p}<0.05$.

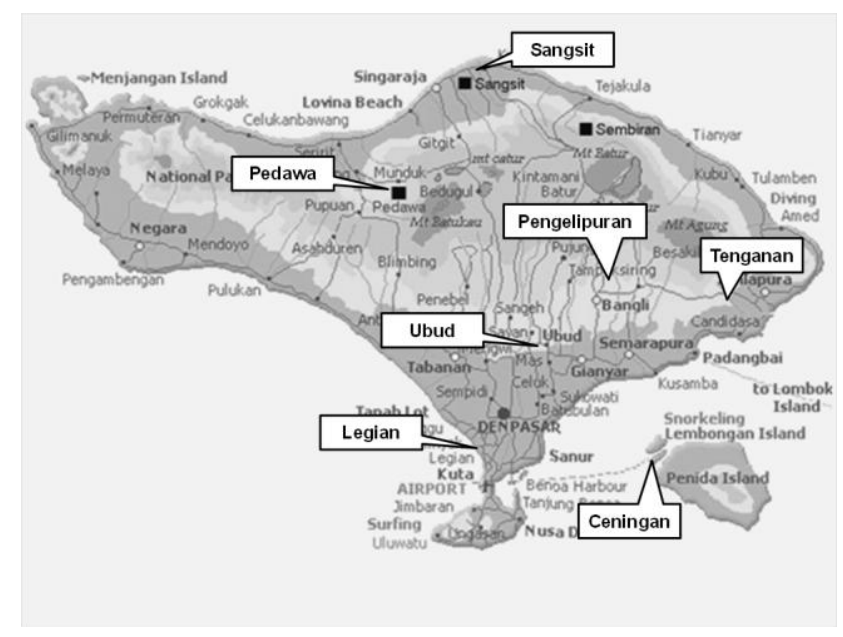

Figure 1. Map of Bali showing the locations of the seven villages used in the study

\section{Results}

We found that male subjects had higher stature and body weight, waist circumference, and levels of triglyceride, and lower levels of HDL cholesterol compared to female subjects. In general, the mean values of all the measured variables were within normal ranges (Table 1).

\section{Table 1. Characteristics of the study subjects}

\begin{tabular}{|c|c|c|c|c|}
\hline & $\begin{array}{c}\text { Male } \\
(\mathrm{N}=972)\end{array}$ & $\begin{array}{c}\text { Female } \\
(\mathrm{N}=\mathbf{8 6 8})\end{array}$ & $\begin{array}{c}\text { Total } \\
(\mathrm{N}=1840)\end{array}$ & $\begin{array}{c}\mathrm{P} \\
\text { (Male vs. Female) }\end{array}$ \\
\hline Age (years) & $44.4 \pm 14.4$ & $43.8 \pm 14.3$ & $44.1 \pm 14.4$ & 0.387 \\
\hline Height $(\mathrm{cm})$ & $163.5 \pm 7.5$ & $153.0 \pm 6.3$ & $158.6 \pm 8.7$ & $<0.001$ \\
\hline Weight (kg) & $61.5 \pm 12.9$ & $53.1 \pm 11.0$ & $57.6 \pm 12.7$ & $<0.001$ \\
\hline Body mass index (kg/m2) & $22.9 \pm 4.2$ & $22.6 \pm 4.4$ & $22.8 \pm 4.3$ & 0.142 \\
\hline Waist circumference $(\mathrm{cm})$ & $82.0 \pm 11.7$ & $77.9 \pm 12.2$ & $80.1 \pm 12.1$ & $<0.001$ \\
\hline Systolic blood pressure $(\mathrm{mmHg})$ & $120.2 \pm 18.2$ & $120.0 \pm 19.4$ & $120.1 \pm 19.0$ & 0.806 \\
\hline Diastolic blood pressure $(\mathrm{mmHg})$ & $77.1 \pm 10.7$ & $76.3 \pm 10.7$ & $76.8 \pm 10.7$ & 0.127 \\
\hline Fasting blood glucose (mg/dl) & $94.9 \pm 26.0$ & $94.1 \pm 34.4$ & $94.6 \pm 30.3$ & 0.582 \\
\hline Total-cholesterol $(\mathrm{mg} / \mathrm{dl})$ & $186.6 \pm 38.8$ & $190.0 \pm 38.4$ & $188.2 \pm 38.6$ & 0.065 \\
\hline LDL-cholesterol (mg/dl) & $122.2 \pm 31.4$ & $120.9 \pm 31.6$ & $121.7 \pm 31.5$ & 0.511 \\
\hline HDL-cholesterol (mg/dl) & $46.7 \pm 11.5$ & $54.2 \pm 14.7$ & $50.3 \pm 13.6$ & $<0.001$ \\
\hline Triglyceride $(\mathrm{mg} / \mathrm{dl})$ & $133.6 \pm 79.2$ & $106.4 \pm 63.6$ & $120.7 \pm 73.5$ & $<0.001$ \\
\hline
\end{tabular}

\begin{tabular}{|c|c|c|c|c|}
\hline & $\begin{array}{c}\text { Male } \\
(\%)\end{array}$ & $\begin{array}{c}\text { Female } \\
(\%)\end{array}$ & $\begin{array}{c}\text { Total } \\
(\%)\end{array}$ & $\begin{array}{c}\text { P } \\
\text { (Male vs. Female) }\end{array}$ \\
\hline \multicolumn{5}{|l|}{ Nutrition state } \\
\hline Underweight $\left(\mathrm{BMl}<18.5 \mathrm{~kg} / \mathrm{m}^{2}\right)$ & 11.2 & 14.9 & 12.9 & 0.219 \\
\hline Normoweight (BMI, $18.5-22.9 \mathrm{~kg} / \mathrm{m}^{2}$ ) & 45.2 & 43.1 & 44.2 & \\
\hline Overweight at (BMl, $\left.23-24.9 \mathrm{~kg} / \mathrm{m}^{2}\right)$ & 16.8 & 16.3 & 16.6 & \\
\hline Obesity I (BMI $\left.\geq 25-29.9 \mathrm{~kg} / \mathrm{m}^{2}\right)$ & 21.1 & 19.9 & 20.5 & \\
\hline Obesity II (BMI $\left.\geq 25-29.9 \mathrm{~kg} / \mathrm{m}^{2}\right)$ & 5.7 & 5.8 & 5.7 & \\
\hline \multirow{2}{*}{\multicolumn{5}{|c|}{ Central obesity (waist circumference, $\geq 90$}} \\
\hline & 27.5 & 43.4 & 35.0 & $<0.001$ \\
\hline
\end{tabular}


Although no differences were found in the prevalence of nutritional state between male and female subjects, central obesity was seen more frequently in female subjects (43.4\% vs. $27.5 \%, \mathrm{p}<0.001$ ) (Table 2). Analysis across the villages showed that Legian and Ubud, apparently the more prosperous villages as they are popular tourist destinations in Bali, have highest prevalence of central obesity $(61.2 \%$ and $70.1 \%$, respectively), but comparable prevalence of DM with other villages. Meanwhile, Pedawa village, a mountainous area, and Ceningan village, an offshore remote area, have the lowest prevalence of central obesity ( $12.8 \%$ and $17.7 \%$, respectively).

The prevalence of MS was $18.2 \%$, and analysis by sex and villages showed that 5 out of 7 villages had higher prevalence of MS in the female subjects as compared with that in the male (Figure 2). Figure 3 shows that subjects having 1, 2, and 3 diagnostic criteria of MS were more frequently seen than those having 4 or 5 features, this applies for both the male and female subjects.
Table 3. Prevalence of impaired fasting glycemia and diabetes mellitus, by sex

\begin{tabular}{lcccc}
\hline Classification & $\begin{array}{c}\text { Male } \\
\mathbf{( \% )}\end{array}$ & $\begin{array}{c}\text { Female } \\
(\mathbf{\%})\end{array}$ & $\begin{array}{c}\text { Total } \\
(\mathbf{\%})\end{array}$ & $\begin{array}{c}\mathbf{P} \\
\text { Male vs. Female }\end{array}$ \\
\hline Normoglycemia & 79.6 & 80.6 & 80.7 & 0.496 \\
Impaired fasting glycemia & 14.3 & 12.4 & 13.4 & \\
Diabetes mellitus & 6.1 & 5.7 & 5.9 & \\
\hline & & & &
\end{tabular}

\section{Discussion}

In our study, although there were no differences in the nutritional state between male and female subjects, central obesity was found more frequently in the female subjects. The total prevalence of central obesity was $35.0 \%$. Analysis across the villages showed that Legian and Ubud, which are the most prosperous villages being popular tourist destinations in Bali, have the highest prevalence of central obesity; and Pedawa village, a mountainous area, and Ceningan village an offshore remote area, have the lowest prevalence of central obesity. The prevalence of overweight and obesity based on the body mass index was $16.6 \%$ and $26.2 \%$, respectively.

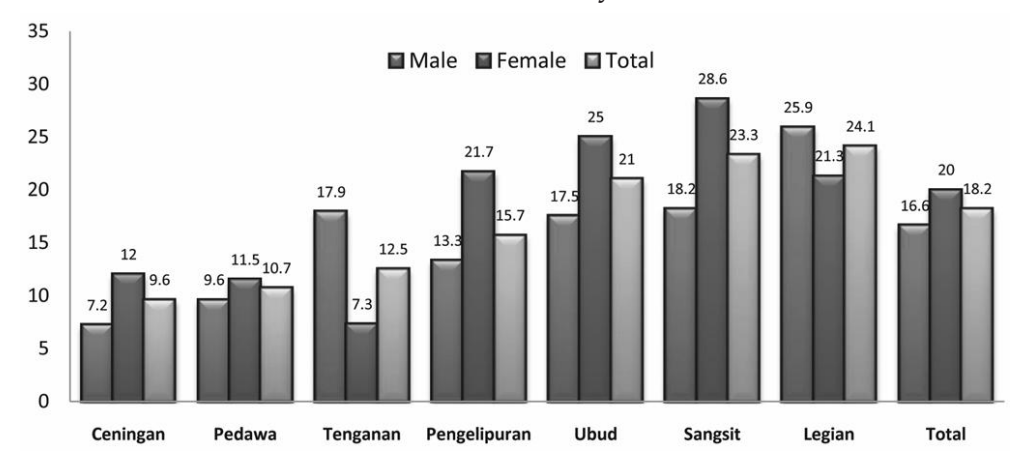

Figure 2. The prevalence of metabolic syndrome by sex and village

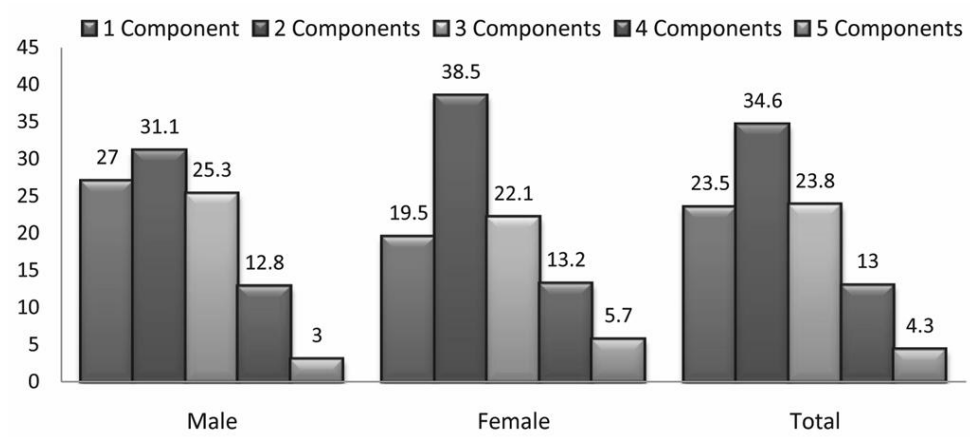

Figure 3. Prevalence of the components of metabolic syndrome by sex

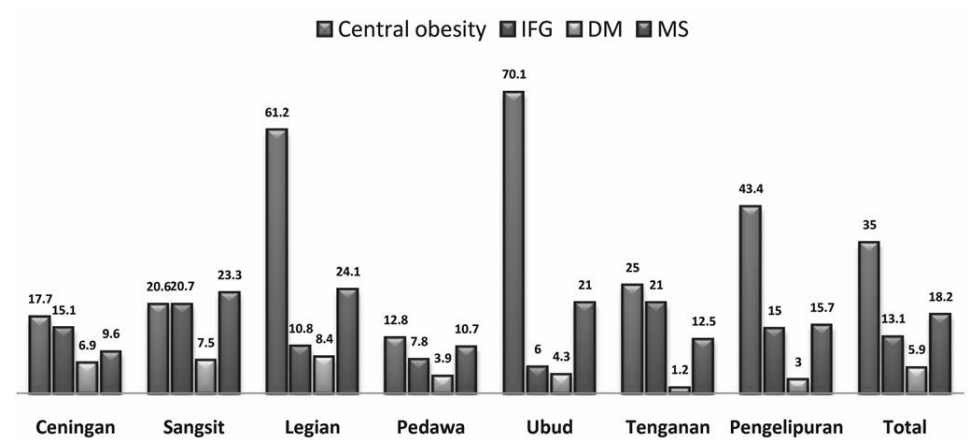

Figure 4. The prevalence of central obesity, impaired fasting glycemia (IFG), diabetes mellitus (DM), and metabolic syndrome (MS,) by village 
The prevalence of overweight and obesity in the adult Kuwaiti population were $80.4 \%$ and $47.5 \%$. Overweight and obesity rates were higher in women $81.9 \%$ and $53 \%$ as compared with men $78 \%$ and $39.2 \%$, respectively. ${ }^{9}$ Ageand gender-adjusted overweight prevalence varied by region of birth and ranged from $24.4 \%$ among central Asian migrants to $64.4 \%$ among Mexican migrants..$^{10}$ Overall, the prevalence of overweight and obesity among Balinese population were lower than other countries.

The prevalence of MS in our study was $18.2 \%$. The prevalence of MS varies according to several factors such as different diagnostic criteria used, differences in ethnicity or race, age, and sex. The Framingham Offspring Study found a prevalence of metabolic syndrome of $29.4 \%$ among 1144 males and $23.1 \%$ among 1295 females aged 26-82 years. ${ }^{11}$ The WHO MONICA study by MarquesVidal, et al., conducted in France, found a 23\% prevalence of metabolic syndrome among males and a prevalence of $12 \%$ among females, with the highest prevalence found in the age group of 55-64 years. ${ }^{12}$ A study conducted in Makassar, Indonesia, involving 330 males, aged 30-65 years, using the NCEP ATP III criteria found that the prevalence of MS was $33.9 \%$. In the group of males with central obesity, the prevalence increased to $62 \% \cdot{ }^{13}$ Comparing with other findings, the prevalence of MS among Balinese people was lower than those found in other countries. Low prevalence of MS was especially seen among native Balinese and in people living at some mountainous areas. Food intake and physical activity, beside race or ethnicity, might influence the findings

In our study, the prevalence of IFG and DM were 13.1\% and $5.3 \%$, respectively. There was no difference in the prevalence of IFG and DM between male and female subjects. The age-standardized prevalence of DM in 3000 adults (52\% women) of Malay ethnicity (40-80 years) in Singapore was $18.4 \% .^{14}$ The age-adjusted prevalence of IFG and DM diabetes in the Korean population were $23.9 \%$ and $7.6 \%$, respectively. ${ }^{15}$ A study on US immigrants showed that age- and gender adjusted DM prevalence ranged from 3.1\% among European migrants to $10.0 \%$ among migrants from the Indian subcontinent. Migrants from the Indian subcontinent had the highest DM prevalence, significantly higher than migrants from any other region, except Mexico and Africa. ${ }^{10}$ In this study, the prevalence of IFG and DM was lower than other findings. Similar to MS, the low prevalence of IFG and DM were especially seen among native Balinese and dwellers in some mountainous areas.. Analysis by village showed the prevalence of DM was always lower than that of IFG. The village which has a higher prevalence of IFG actually does not always have a higher prevalence of DM.

Moreover, a summary of the results across the villages indicated that population in highland village (Pedawa) and remote island (Ceningan) have the lowest prevalence of central obesity; conversely the highest prevalence of central obesity were found in tourist areas (Legian and Ubud) population. We have no supporting data but by observation, it may be caused by the difference in income and physical activities of daily living. Similar to obesity, the highest prevalence of MS were also found in two tourist areas, as well as in Sangsit village. The high prevalence of hypertension in Sangsit village (a coastal area) compared with other villages contributed to the higher prevalence of MS in this village. The study showed that a village with a high prevalence of central obesity was not always associated with a high prevalence of MS and DM. Diabetes mellitus, like hypertension, is a common, complex, and multi-factorial disease whose exact underlying mechanism is largely unknown given our current state of research. The result of this study can be a data base for further studies and action plans for health promotion in Bali, especially in tourist areas.

\section{Acknowledgements}

This study was funded by the Udayana University Faculty of Medicine, Denpasar, Indonesia; Indonesian Endocrinology Society, Bali Branch, Denpasar, Indonesia; Kobe Women's University, Japan; and partly supported by a Grant-in-Aid for Scientific Research (B): Overseases (Grant No. 12576021 and 20406018) from the Japan Society for the Promotion of Science, Japan. The authors declare no complict of interest regarding this article.

\section{References}

1. Day C. Metabolic syndrome, or what you will: Definition and epidemiology. Diabetes Vasc Dis Res. 2007; 3: 32-8.

2. Executive summary of the third report of the National Cholesterol Education Program (NCEP) Expert Panel on Detection, Evaluation and Treatment of high blood cholesterol in adults (Adult Treatment Panel III). JAMA. 2001; 285: 2486-2497.

3. World Health Organization. Definition, diagnosis and classification of diabetes mellitus and its complication. Part 1: Diagnosis and classification of diabetes mellitus. WHO, Geneva 1999.

4. Cameron AJ, Shaw JE, Zimmet PZ. The metabolic syndrome: Prevalence in worldwide populations. Endocrinol Metab Clin N Am. 2004; 33: 351-375.

5. Henry RR, Mudaliar S. Obesity, mechanisms and clinical management. Eckel RH (Ed.) Lippincott Williams \& Wilkins, Philadelphia 2003; 229-72.

6. The Asia-Pacific perspective: Redefining obesity and its treatment. World Health Organization Collaborating Centre for the epidemiology of diabetes mellitus and health promotion for non-communicable disease. Melbourne 2000.

7. American Diabetes Association. American Diabetes Association. Diagnosis and classification of diabetes mellitus. Diabetes Care. 2009; 32 (Suppl. 1): S62-S67.

8. Alberti KGMM, Eckel RH, Grundy SM, et al. Harmonizing the metabolic syndrome. A joint interim statement of International Diabetes Federation, National Heart, Lung, and Blood Institute, American Heart Association, World Heart Federation, International Atherosclerosis Society, and International Association for the Study of Obesity. Circulation. 2009; 120: 1640-1645.

9. Rashdan IA and Nesef YA. Prevalence of overweight, obesity, and metabolic syndrome among adult Kuwaitis: Results from Communitybased National Survey. Angiology. 2010; 61: 42 - 48.

10. Oza-Frank R, and Venkat Narayan KM. Overweight and diabetes prevalence among US immigrants. Am J Public Health. 2010; 100: 661-668.

11. Ford ES. Prevalence of the metabolic syndrome in US populations. Endocrinol Metab Clin N Am. 2004; 33: 333-350.

12. Marques-Vidal P, Mazoyer E, Bongard V, et al. Prevalence of insulin resistance syndrome in southwestern France and its relationship with inflammatory and hemostatic markers. Diabetes Care. 2002; 25: 1371-1377.

13. Herman A, Adam JMF, Sanusi H, Sambo AP. Waist circumference as a screening approach of metabolic syndrome in men. Abstract of the $12^{\text {th }}$ Congress of the ASEAN Federation of Endocrine Societies, Singapore 2003.

14. Sabanayagam C, Shankar A, Saw SM, Tai ES, Lim SC, Lee JJM, Wong TY. Prevalence of diabetes mellitus, glycemic control, and associated factors in a Malay population in Singapore. Asia Pac J Public Health. 2009; 21: 385 398.

15. Kim SM, Lee JS, Lee J, et al Prevalence of diabetes and impaired fasting glucose in Korea. Korean National Health and Nutrition Survey 2001. Diabetes Care. 2006; 29: 226-231. 